\title{
Dos Tiempos para la Utopía: Festivales de Cine Latinoamericano
}

\section{Twice for Utopia: Latin American Film Festivals}

\author{
José Román R. \\ Instituto de Estética. Pontificia Universidad Católica de Chile. Santiago \\ joroman@uc.cl
}

\begin{abstract}
Resumen - Los dos festivales de cine latinoamericano celebrados en Viña del Mar en 1967 y 1969, tuvieron como tema principal las relaciones entre cine y política. Las películas presentadas provenían de movimientos caracterizados como «nuevo cine», en oposición al que dominaba las pantallas del continente. La mayoría de ellas buscaban representar la realidad social y política de sus países. En paralelo a la exhibición de los filmes, los cineastas invitados debatían sobre los grandes temas que agitaban al continente en esos años (inequidad social, dependencia cultural, regímenes dictatoriales, violencia política) y las propuestas estéticas, culturales y políticas en que cada país y movimiento basaba sus experiencias cinematográficas. El presente artículo analiza los filmes y propuestas teóricas más importantes que caracterizaron tanto las muestras como los encuentros de cineastas latinoamericanos.
\end{abstract}

Palabras clave: Documental, cine-encuesta, realidad, dependencia, revolución.

Abastract - The two Latin American film festivals that were carried out in Viña del Mar in 1967 and 1969 were connected by their themes: the bonds between films and politics. The exhibited films come from movements known as the «new cinema», which was opposed to the commercial films screened in movie theaters all around the continents. Most of them were trying to represent the social and politic reality in their countries. In parallel to the films screening, the invited filmmakers debated about themes that were relevant to context of the continent in those years (social inequality, cultural dependence, dictatorial regimes, police violence) as well as the aesthetics, cultural and political proposals in which every country based its cinematogrphic experiences. Thus, the following article will analyze the most important films and theoretical proposals that characterised those screening, as well as the invited Latin American filmmakers.

Keywords: Documentary, cinematographic survey, reality, dependence, revolution. 
Los dos Festivales de Cine Latinoamericano y encuentros de cineastas del continente los años 1967 y 1969, llevados a cabo en la ciudad de Viña del Mar, constituyeron hitos importantes tanto por su repercusión internacional como por la evolución que experimentaría el cine chileno a partir de entonces hasta 1973 y que proseguiría más tarde con gran vitalidad en el llamado «cine del exilio».

Las siguientes líneas tienen por objeto una aproximación diacrónica señalando algunos rasgos que marcaron un proceso. La revisión de ese período no pretende ser un recuento histórico exhaustivo de los filmes participantes, sino un estudio de aquellas películas y movimientos que caracterizaron la presencia del tema abordado. Para ello, hemos escogido la clasificación por países y autores siguiendo una línea cronológica que nos permite identificar el proceso evolutivo tanto de la filmografía reseñada, como de las propuestas estéticas, culturales y políticas que se desarrollaron en el curso de estos eventos. Existen algunos textos que dan cuenta de la organización, desarrollo y resultados de ellos, pero carecen de una aproximación epistemológica y sistemática a los contenidos de los filmes exhibidos. Agradecemos sí la transcripción de documentos y manifiestos que contribuyeron a este trabajo. Documentos imprescindibles son también los textos publicados por los mismos realizadores y participantes, así como los libros que se abordaron metodológicamente el nuevo cine latinoamericano.

Hemos reducido al mínimo las reseñas del «nuevo cine chileno» por cuanto existe ya una abundante y documentada bibliografía al respecto, privilegiando el espacio para otras filmografías menos conocidas en nuestro país.

\section{ANTECEDENTES}

Las relaciones entre el cine y la política han estado siempre en la reflexión teórica desde diversas perspectivas. Al fin y al cabo se trata de un arte polisémico, cuyos vínculos con las imágenes y relatos del mundo real constituyen su principal especificidad, como lo señalaran Bazin, Kracahuer, Pasolini y otros. Y en la realidad diegética encarnada en la pantalla suelen emerger indicaciones que aluden a las relaciones de poder o a la manera en que se organiza el orden social. No es extraño entonces que, por ejemplo, en las películas de ficción este ámbito se constituyera en un subgénero, tanto en el cine soviético de los primeros años (Eisenstein, Pudovkin) y en el período clásico norteamericano (Frank Capra, Herbert Biberman) como en el cine italiano postneorrealista (Francesco Rosi, Elio Petri).

En Latinoamérica, espacio constituido por diversas condiciones de desarrollo en el terreno cinematográfico, el tema político no estuvo ausente en sus primeros cincuenta años, como lo testimonian los filmes sobre la revolución mexicana de Fernando de Fuentes o películas como Deja que los perros ladren, del chileno Naum Kramarenco.

Sin embargo, esta presencia alcanzó su máxima expresión en la década del sesenta, abarcando diversos niveles: conciencia de una identidad latinoamericana, homogeneización del diagnóstico y los objetivos, identificación de nuevos actores como sujetos de la representación y como destinatarios de los filmes proyectados.

Hay diversos factores intra y extra cinematográficos que facilitarán esta percepción. 
Por una parte, desde que Croce reconociera al cine su status artístico, el fenómeno había empezado a ser estudiado por académicos e intelectuales y a ser integrado en el terreno de la «gran cultura» desde diversas perspectivas. La conciencia del cine como posibilidad estética, antropológica, sociológica o histórica había ido extendiendo cada vez más la idea de "otro" cine, diferente del producto meramente comercial destinado a entretener a un público, como podrían hacerlo el teatro ligero o el vodevil. El tema de la "función» del cine, su "coeficiente de realidad», su cualidad especular, conduce a una ontología que deriva en imperativos estéticos, sociales e incluso morales. Pero tampoco están ajenas a estas nuevas miradas los estudios sobre los efectos que ese cine «de entretención» produce en las audiencias a partir de su carácter persuasivo: reproducción directa o indirecta de la ideología dominante, evasión o distorsión de la percepción de las relaciones sociales. A partir de estos parámetros se elaboran las propuestas de una diversidad, cuando no de una oposición frontal.

Se asume, además, que no se puede observar al cine desde una óptica puramente estética o socio-cultural sin atender a las instancias de producción y difusión, esta última considerando sus etapas de distribución y exhibición. Esta cadena de elaboración industrial, a la que el cine está fatalmente condenado, se inserta en una sociedad, una economía, una institucionalidad y un ámbito cultural, que inciden de una u otra manera en la forma que el cine se instala en el espacio social con relación a sus destinatarios. Por ejemplo, una entidad gravitante por casi ochenta años fue la censura cinematográfica, cuya sola existencia se contradecía flagrantemente con los relativamente recientes consensos sobre la libertad de expresión.

Coincide también la década mencionada con convulsiones políticas, cuestionamientos epistemológicos, nuevas propuestas estéticas y una confianza, casi sin fisuras, en la posibilidad del cambio social.

En Europa habían surgido tendencias como el neorrealismo italiano que no solo proponía una nueva mirada sobre la realidad, sino que daba lugar a un consistente bagaje teórico que tendría una influencia decisiva en los cines del llamado entonces Tercer Mundo. Nociones como la de «realismo crítico» (Guido Aristarco), penetrarían tanto en la mirada de los nuevos realizadores como en las operaciones hermenéuticas de la crítica cinematográfica del continente. Lo seguiría más tarde la «nouvelle vague» con sus propuestas revulsivas en temas y formas o nuevas metodologías de registro e investigación como la del «cine-verdad» de Jean Rouch. La idea de un «nuevo cine» se hacía extensiva a otros cines como el británico, polaco y checoslovaco y no tardaría en dejarse sentir en cinematografías emergentes o sometidas a la reproducción de modelos institucionalizados.

\section{EL CONTINENTE}

A mediados de la década del cincuenta la situación del cine en los países de Latinoamérica era muy diversa y fluctuaba entre naciones que tenían una sólida industria de ese cine «de entretención» que alimentaba también a otros países del continente y aquellas que carecían totalmente de actividad cinematográfica. En un rango intermedio, estaban 
países como Chile, de producción esporádica, imitativa, dependiente culturalmente y destinada a la audiencia interna.

En algunos de estos países empezaba a plasmarse en las universidades la idea de un cine nuevo con propósitos diferentes a los del mercado cinematográfico. Correspondió un rol pionero a la Escuela Documental de Santa Fe de la Universidad del Litoral, en la República Argentina. Allí se incubó, a instancias de su director, el cineasta Fernando Birri, la noción de "foto-documental», como una escuela de aproximación a la realidad y luego la de "cine-encuesta» con la intención de generar una nueva estética apoyada en la investigación socio-antropológica y el testimonio con intención de denuncia de las anomalías sociales. Formado en el Centro Experimental de Cinematografía de Roma, Birri haría manifiesta la influencia recibida del neorrealismo italiano, pero con la intención de superarlo en sus tentativas testimoniales y de registro directo. A partir de sus primeras experiencias, el cineasta fundamentaba su propuesta teórica:

veo en las encuestas documentales un formidable mural adonde el pueblo puede escribir diariamente su biografía para conocimiento del hombre argentino a través de sus afanes, de sus dolores y esperanzas [...] Es que cuando se toma estimación verdadera por las personas reales, cuando uno se sumerge en la peripecia de sus vidas, surge siempre una historia caliente llena de candor que termina por rebasarnos, por conquistarnos definitivamente para su causa personal, que es la causa de la humanidad. Mediante este trabajo que podríamos llamar de rastreo del potencial humano, será el pueblo mismo quien tome participación en el hecho cinematográfico (Birri, 28).

En Chile, la Pontificia Universidad Católica creó el Instituto Fílmico, bajo la dirección del cineasta y en aquel entonces sacerdote, Rafael Sánchez. Además de su función docente, formadora de algunos futuros realizadores como Sergio Bravo, Pedro Chaskel, Patricio Guzmán y el boliviano Jorge Sanjinés, el Instituto produjo algunas obras documentales pioneras del cine chileno testimonial (por ejemplo Las Callampas, documental sobre la marginalidad habitacional, del propio Rafael Sánchez). Poco más tarde, la Universidad de Chile acogió e incorporó al Centro de Cine Experimental creado por Sergio Bravo y con la participación de nuevos cineastas, como Pedro Chaskel y Héctor Ríos, dio lugar a una producción documental que se aventuraba también en zonas inexploradas de nuestra realidad. Los mineros y sus luchas sociales (La marcha del carbón, de Sergio Bravo) la maternidad proletaria desprotegida (Aborto, de Pedro Chaskel), los niños abandonados (Por la tierra ajena, de Miguel Littin), el hombre de la calle encuestado sobre su responsabilidad en el subdesarrollo nacional ( $\dot{\xi}$ s usted culpable?, de José Luis Villalba) o los pobladores desalojados por la fuerza (Herminda de la Victoria, de Douglas Hübner) serían los nuevos protagonistas de la imagen cinematográfica nacional.

Junto a las iniciativas universitarias, algunos documentalistas independientes como la pareja Jorge di Lauro y Nieves Yancovic (Andacollo y San Pedro de Atacama) y el realizador Helvio Soto (Yo tenía un camarada) que se iniciaba en el cine de ficción, sentarían las bases de ese nuevo cine chileno que se anunciaba.

La institución unificadora sería el Festival de Cine de Viña del Mar. Pensado inicialmente como un evento puramente nacional, tuvo una rigurosa continuidad, lo que permitió, ya en su cuarta versión, hacer un catastro de la producción local antes de proyectarse hacia el ámbito continental. 


\section{EL FESTIVAL COMO DETONANTE}

Todo ello tuvo su punto de partida en el Cine Club de Viña del Mar. Es preciso advertir que esta noción de «cine-clubismo» corresponde a una dinámica cultural muy distante de la idea generalizada de «club» como círculos de amigos convocados por una afición común. El Cine Club de Viña del Mar se inicia en torno a proyecciones abiertas de filmes seguidas de debate, incorpora a docentes que imparten cursos sistemáticos, funda una revista especializada -Cine-Foro-, llega a construir — probablemente uno de los pocos casos en el mundo- una nueva sala de cine de 35 y $16 \mathrm{~mm}$. con proyecciones públicas y organiza los primeros festivales de cine del país, centrándose en una primera etapa en el cine realizado en Chile, a menudo por creadores desconocidos que acuden de diversas regiones. Es decir, viene a suplir el rol que en otros países cumplen entidades estatales o universitarias.

En su cuarta versión, en 1966, el Festival incorpora a las instituciones universitarias (Instituto Fílmico de la Universidad Católica y Cine Experimental de la Universidad de Chile), bajo la denominación Primer Festival de Cine Chileno y Primer Encuentro de Cineastas Chilenos. Esta expresión - la de «encuentro»- marcará en lo sucesivo una instancia fundamental en la identidad del evento, ya que la proliferación de debates, ponencias, informes y difusión de documentos terminará por constituir un acervo teórico que movilizará la reflexión y la acción en torno al cine. Esta instancia no es solo teórica sino que aborda los problemas prácticos de la producción, distribución y exhibición de los filmes y allí surgen las bases de la primera ley de protección al cine chileno, que terminará concretándose en la llamada «ley de cine» de 1964. Es esta disposición legal la que va a facilitar el resurgimiento del cine chileno de ficción en los años siguientes.

\section{EL DESCUBRIMIENTO DE AMÉRICA}

El Primer Festival de Cine Latinoamericano, llevado a efecto en 1967, era en realidad el quinto festival organizado por el Cine Club de Viña del Mar. Esta vez la Universidad de Chile emerge como patrocinador, incorporando a los integrantes de la Cineteca Universitaria y de Cine Experimental y anexando una franquicia de especial importancia: sus exhibiciones estaban legalmente exentas de la tuición del Consejo de Censura Cinematográfica. Esta liberación de la exhibición no existía en ningún otro país de América Latina y constituyó, para muchos de los participantes, la posibilidad de presentar filmes vetados o perseguidos políticamente en sus países de origen.

La convocatoria a los cineastas del continente tuvo, además, un atractivo que emanaba de las condiciones políticas favorables que vivía entonces nuestro país y que difería de las de muchas naciones latinoamericanas: Argentina experimentaba la dictadura del general Juan Carlos Onganía que, desde el golpe militar de 1966, paralizaba la producción cinematográfica independiente; en Bolivia, el gobierno del general René Barrientos exiliaba a Jorge Sanjinés, el principal cineasta de ese país; los brasileros sufrían la dictadura de Arturo da Costa e Silva. Por su parte Cuba enfrentaba una situación especial. Estaba representada por un organismo oficial: el Instituto Cubano del Cine. Segregada 
por órdenes del gobierno norteamericano, encontró en el territorio chileno uno de los pocos espacios al que podían acceder sus cineastas y sus obras.

Tanto las condiciones políticas como las características de la distribución cinematográfica habían impedido hasta el momento el conocimiento mutuo de las cinematografías emergentes y este evento permitió, además de la posibilidad de ver las películas, constatar la diversidad de propuestas estéticas y culturales, condiciones de producción y estrategias de exhibición. En ese momento se consolidaba la conciencia de la existencia de un nuevo cine que unificaba a la región en proyectos y objetivos comunes:

Invocando un ideal continental de unidad, asentado en la diferenciación de América Latina, el movimiento se ha alineado con discursos y representaciones a través de las cuales han sido meditadas las historias y culturas latinoamericanas. Más aún, los ideales de solidaridad continental — su unidad dentro de la diversidad — han permitido al movimiento incorporar los objetivos políticos de sus prácticas cinemáticas constitutivas en un proyecto continental y modernista. El despliegue del Nuevo Cine Latinoamericano - como un proyecto ideológico y una práctica cinematográfica- es el resultado de su capacidad de conceptualizar el impacto social y político del cine como práctica cultural. Los impulsos modernistas del movimiento han sido cruciales para la manera en la cual las películas y los realizadores han adoptado al cine como un instrumento crítico (Pick, 2-3).

\section{LA ESCUELA DE SANTA FE. Y UN FILME-MANIFIESTO}

La labor pionera de la mencionada Escuela Documental de Santa Fe estuvo representada por un conjunto de obras que ofrecían además una metodología de trabajo y propuestas epistemológicas novedosas que contribuían al debate e intercambio de experiencias.

Los filmes de Fernando Birri, Tire die y Los inundados, exhibidos y premiados en festivales europeos, se presentaban uno como modelo del llamado documental-encuesta, y otro del documental ficcionalizado, y eran, además, la plasmación de un método, una definición política y una propuesta teórica respaldados por un libro del propio Birri, titulado La Escuela Documental de Santa Fe. Una experiencia piloto contra el subdesarrollo cinematográfico en Latinoamérica, publicado por la Universidad Nacional del Litoral. En su introducción, exponía su concepción del género:

¿Cómo da esa imagen el cine documental? La da como la realidad es y no puede darla de otra manera. (Esta es la función revolucionaria del documental social en Latinoamérica). Y al testimoniar cómo es esta realidad —esta subrealidad, esta infelicidad - la niega. Reniega de ella. La denuncia, la enjuicia, la critica, la desmonta. Porque muestra las cosas como son, irrefutablemente, y no como querríamos que fueran. (O como nos quieren hacer creer — de buena o mala fe- que son) (Birri, 13).

El texto citado, en su versión completa, fue incorporado como «El Manifiesto de Santa Fe» por Paulo Antonio Paranaguá en su obra El documental en Latinoamérica junto a otros escritos fundacionales (Paranaguá, 456).

Tire die fue la primera experiencia del documental-encuesta, según la terminología de Birri. Sus protagonistas son pobladores marginales de los suburbios de Santa Fe y los niños mendigos que corren tras las monedas que les arrojan los pasajeros del tren que une su ciudad con Rosario y Buenos Aires. 
Con el paso de los años, se ha revalorizado su rol pionero en el cine latinoamericano que empezaba a surgir, como lo advierte el citado libro de Paranaguá: Birri nos apunta con la imagen porque cree que la función del documental social en Latinoamérica es la de no escamotear al pueblo, sino denunciar, enjuiciar, criticar y desmontar la realidad que documenta. Es uno de los primeros cineastas en proponer un cine que fortalezca la identidad de los pueblos del continente, «un cine que le dé conciencia, toma de conciencia; que los esclarezca; que fortalezca la conciencia revolucionaria de aquellos que ya la tengan; que los fervorice, que inquiete, preocupe, asuste, debilite a los que tienen ‘mala conciencia), conciencia reaccionaria...» (Paranaguá, 289)

Este texto reivindicativo da cuenta, además, de la retórica que caracterizaba las propuestas programáticas de este nuevo cine.

Resulta notable la similitud temática y formal con el filme Las Callampas realizado por Rafael Sánchez en el Instituto Fílmico de la Universidad Católica en 1958. Ambas comparten, además, a diferencia de la pulcritud técnica de los documentales de encargo de la época, las huellas de la precariedad de sus medios de producción, a pesar de las cuales lograban imponerse por la intensidad de sus imágenes y la fuerza testimonial. Adelantándose a la polémica que desataría años más tarde el cubano Julio García Espinosa con su teoría del "cine imperfecto», Birri escribía: «Las imperfecciones de fotografía y de sonido de Tire Die se deben a los medios no profesionales con los cuales se ha trabajado forzados por las circunstancias, las cuales al obligar a una acción y a una opción han hecho que se prefiriera un contenido a una técnica, un sentido imperfecto a una perfección sin sentido» (Birri, 51).

La aparentemente forzada opción por el formato $16 \mathrm{~mm}$., que dificultaba o simplemente impedía la proyección de muchos de los documentales latinoamericanos en salas de cine comerciales, facilitaba en cambio la diversificación de públicos menos numerosos en salas universitarias, escolares, sindicales o centros culturales, que incorporaban el diálogo y el contacto de los realizadores con su público, cuando no, en funciones directamente clandestinas, como ocurría en países afectados por la represión política. Este tema, debatido en el curso de los encuentros del Festival, conduciría más tarde al realizador trasandino Octavio Getino a hablar de la "comunicación horizontal», diferente de aquella que se establece en una sala comercial, con un espectador pasivo e inopinante.

Los inundados implicó para Birri una opción diversa. Largometraje filmado en 35 $\mathrm{mm}$., en condiciones técnicas profesionales, asimiló directamente la influencia neorrealista. Basada en un relato (de Mateo Booz) — similar en esto a la experiencia de La Tierra Tiembla, de Visconti-, ficcionalizaba la catástrofe que sufrían estacionalmente los habitantes de un sector de Santa Fe. Utilizando a actores no profesionales y a los verdaderos habitantes del lugar — como lo hiciera también Visconti-, el filme, en tono de sátira, testimoniaba la inoperancia de un sistema político incapaz de prever y resolver un agudo problema social que se repetía año a año.

Obra coral, multitudinaria, integró a toda una comunidad como intérpretes y espectadores del proceso creador, reviviendo sacrificadamente durante el rodaje sus propias experiencias. También, al decir de Birri, fue un «filme-escuela», que incorporó como práctica docente a los estudiantes de cine de la Universidad del Litoral (Birri, 210).

Otras obras de la Escuela de Santa Fe participaron, en competencia, en ese Primer Festival Latinoamericano, dando cuenta de su coherencia de objetivos y diversidad temática. Las cosas ciertas, de Gerardo Vallejo, describía el trayecto en ferrocarril de un 
trabajador temporero de la zafra azucarera, desde Tucumán a Río Negro, hacia su nuevo destino: la cosecha de la manzana (Vallejo, 33). Se trata de una especie de «estética del seguimiento» que Vallejo proseguirá más tarde con su filme más célebre: El camino hacia la muerte del Viejo Reales, que, a través de la vida de una familia campesina, nos aproximaba a las duras formas de existencia en el mundo subdesarrollado.

Otros ejemplos son Greda, de Raymundo Gleyzer, «documental que muestra un panorama de miseria y éxodo de provincia, a través de la vida de una anciana que va quedando sola y cuyo trabajo es hacer cántaros y ollas de greda» (Francia, 132) y Hachero nomás de Jorge Goldenberg, acerca de los trabajadores de un latifundio maderero. También Hoy cine Hoy, de Diego Bonacina, reportaje sobre proyecciones de cine ambulante en una zona rural distante que registra las reacciones y opiniones de sus espectadores y sus precarias condiciones de existencia. La itinerancia y el desarraigo de comunidades empobrecidas aparecen como ejes de estas historias, apuntando directa o indirectamente a la responsabilidad del sistema político imperante.

Con temas centrados principalmente en su realidad local, los documentales de la Escuela de Santa Fe encontrarían en el Festival una manifiesta afinidad con otras obras del continente, lo que confirmaría en sus realizadores la idoneidad del método y los objetivos propuestos al coincidir estos con los de otras cinematografías.

\section{CINEMA NOVO}

Junto con Argentina y México, Brasil tenía una industria cinematográfica con una producción que lograba financiarse en el mercado interno. Como en esos países, se trataba de filmes comerciales sin pretensiones estéticas ni culturales. Tomando como modelos ciertas obras pioneras ajenas a esos afanes y sólidamente asentadas en la cultura brasilera, como los filmes de Humberto Mauro y Alberto Cavalcanti, se había gestado un movimiento de jóvenes cineastas que llegaron a constituir aquello que se llamó el Cinema Novo.

Su presencia en el Festival fue una de las más generosas: 18 documentales y la exhibición fuera de competencia del largometraje Dios y el diablo en la tierra del sol, de Glauber Rocha, obra emblemática de movimiento. El mismo realizador había caracterizado años antes algunos rasgos preponderantes de ese cine nuevo:

Percibimos el valor intelectual de los cineastas, que son hombres venidos de la cultura cinematográfica al cine y no procedentes de la radio, del teatro o de la literatura. O si no, procedentes del pueblo mismo, con la visión de artistas primitivos, creadores anónimos a lo largo de la civilización metropolitana [...] La expansión crece, y, aunque seamos visionarios, afirmaremos que la cultura brasileña está entrando en la edad del cine, cuando el viejo mundo se consume en el último pensamiento de la «nueva ola» [...]

...Queremos un crédito de confianza. No deseamos nada más. Y, en caso de que no aparezcan inmediatamente estas ayudas — de elementos que existen y que no necesitan ser importados - vamos a hacer nuestras películas como podamos; con la cámara en la mano, en $16 \mathrm{~mm}$ (si no hubiera 35 ), improvisando en la calle, montando material ya existente (Rocha, 79-81). 
Sin embargo el cinema novo, a diferencia de la Escuela de Santa Fe, contó desde un comienzo con equipamiento profesional. La posibilidad de filmar con sonido directo les permitió desarrollar los mecanismos del cine-encuesta hasta transformarlos en la metodología fundamental no solo del cine documental, sino en frecuentes manifestaciones de intertextualidad en el cine de ficción. Rocha reconoce la influencia del documentalista francés Jean Rouch con su método y teoría del cine directo o «cine-verdad». «Es preciso no olvidar a Jean Rouch, autor de un cine-verdad sin ningún artificio, cine sin trípode, sin maquillaje, sin ambientes que no sean los reales - cámara en la mano, bajo costo de producción, para mostrar el verdadero gesto del hombre» (Rocha, 82).

Formando un movimiento orgánico e interconectado, los documentalistas del cinema novo se agrupan en torno al productor Thomaz Farkas, camarógrafo, además, de algunas de sus películas. Junto a él trabaja el productor ejecutivo Edgardo Pallero, proveniente de la Escuela de Santa Fe y uno de los gestores de los festivales de cine. Los documentales presentados en éste por el «grupo Farkas» indagaban en temas tan dispares como el racismo, el analfabetismo, el fútbol, el Carnaval, ofreciendo una visión del Brasil desconocida para la audiencia. Integración racial, de Paulo César Saraceni, desmentía con la fuerza de una verdad registrada en directo, la ficción oficial de que Brasil era un país racialmente integrado; Subterráneos del fútbol, de Maurice Capovilla desmitificaba este deporte popular, fuente de ilusiones de éxito para los jóvenes de sectores marginados, lugar de explotación esclavizante para los jugadores profesionales, detonante de fanatismo e irracionalidad en los hinchas y generador de dividendos para los dirigentes; Mayoría absoluta, de Leon Hirszman, comprueba testimonialmente la exactitud de su título con las cifras de analfabetismo existentes entonces en Brasil; Nuestra escuela de samba, de Manuel Horacio Jiménez, contrastaba los afanes en torno a la experiencia de cultura popular suscitada por el Carnaval de Río y la miseria de sus protagonistas, los habitantes de las favelas; Viramundo, de Geraldo Sarno, trataba la emigración hacia Sao Paulo de los empobrecidos campesinos del Nordeste, sus dificultades de adaptarse al trabajo urbano que conduce a «un análisis de la sociedad industrial en términos de clase» (Bernardet, 120) y documentaba sus manifestaciones sincréticas de religiosidad popular.

La revisión histórica desde una perspectiva diferente a las versiones oficiales surgía a menudo en el cinema novo, sobre todo evocando acontecimientos que comprometían o cuestionaban los intereses políticos dominantes. Memorias del cangaço, de Paulo Gil Soares, describe, a través de algunos de sus protagonistas, un episodio del pasado: la acción del gobierno para exterminar a los cangaceiros, grupos armados organizados que dominaban el sertao nordestino, espacio de miseria y abandono. La crudeza de las declaraciones de los entrevistados, militares sobrevivientes de esa época, se alterna con imágenes filmadas de Lampiao, uno de los principales jefes del cangaço, junto a su gente. El filme termina mostrando las cabezas decapitadas de los cangaceiros, puestas en exhibición por el poder triunfante: imagen emblemática de una América que, sin embargo, se veía a sí misma instalada en la modernidad.

La documentación rigurosa de Memorias del cangaço se transmutará en leyenda en manos de los realizadores de ficción. Glauber Rocha, en Dios y el diablo en la tierra del sol construye en torno a la historia del Nordeste un poema coral y violento, recuperando la visión mítica popular del cangaceiro Corisco, uno de los decapitados del documental de Gil Soares y del santón Antonio Conselheiro, protagonista real de la llamada «guerra de Canudos». Al hablar de este Brasil mítico y violento, Glauber Rocha aludía también 
a su presente caracterizado por dictaduras, represión, violencia, abandono y pobreza de extensas zonas de su territorio: «El cangaceiro es un rebelde contra la organización social en la región en que vive; al margen de la sociedad pasa a atacarla. Pero su rebelión es anárquica: persigue la destrucción y eventualmente proteger a los campesinos desamparados, pero nada propone» (Bernardet, 40 ).

En las antípodas del filme poético, barroco, de Rocha, Nelson Pereira dos Santos realiza con Vidas secas, una obra austera y contenida que combina la sensibilidad del neorrealismo con la soltura documental del nuevo cine. Basado en la novela de Graciliano Ramos, retoma el tema del Nordeste a través de una familia campesina errante que no encuentra un lugar donde habitar, paradoja extrema atendiendo la extensión territorial de Brasil. Sus protagonistas sufren, además, la injusticia y violencia de la autoridad. En un estudio de la obra del realizador, Glauber Rocha la sitúa en el realismo-crítico (Rocha, 67). Pereira dos Santos se refiere así a su filme: «En la época en que hice Vidas secas no había ninguna producción académica que planteara tan claramente la cuestión de la población nordestina, nada tan fuerte y directo. $\mathrm{Y}$ en el cine tal vez ni siquiera hasta hoy se haya conseguido abordar, con tamaña radicalidad, el problema de la sequía en el Nordeste, de la concentración de la propiedad de las tierras y de las relaciones de poder en el campo brasileño» (cit. en Salem, 165).

\section{EL INSTITUTO CUBANO DEL CINE}

El único país participante en que el cine aparecía directamente incorporado a su institucionalidad cultural y producido directamente por un ente estatal, el I.C.A.I.C., era Cuba. Con una historia cinematográfica irrelevante hasta el cambio político, el cine cubano nacía ya como un nuevo cine y contando con un fuerte respaldo tecnológico. Su representante en la muestra documental era Santiago Álvarez, cuyos filmes se presentaban como directamente políticos —el mismo Álvarez los llamaba «panfletos»-, volcándose a temas polémicos de su actualidad nacional e internacional. Elaborados en parte con filmaciones directas y mayormente en la mesa de trucajes y animación, Álvarez construía verdaderos collages de imagen y sonido, recuperando el concepto de «montaje expresivo» de Eisenstein, todo ello con el dinamismo adquirido en su práctica cotidiana como director del Noticiero I.C.A.I.C. Latinoamericano, mostrado también en el Festival.

En Now, mediante una combinación de imágenes de noticieros, fotografías de prensa y animaciones gráficas, aludía a la violencia del conflicto racial en Norteamérica, entonces en pleno auge. En Cerro Pelado registra la participación, triunfal, de Cuba en los Juegos Olímpicos Centroamericanos celebrados en Puerto Rico y la hostilidad sufrida por la delegación cubana de parte de las autoridades de ese país, Estado asociado institucionalmente a los EE.UU.

Otro filme participante de Cuba fue Manuela, de Humberto Solás. Uno de los escasos cortometrajes de ficción presentados, narra la historia de una joven campesina incorporada a la guerrilla. Herida de muerte en una batalla contra el ejército regular, persuade a su novio de no tomar venganza contra el enemigo hecho prisionero por los guerrilleros.

La presencia cubana ocupaba también un importante lugar en el debate ideológico y estético, mediante la participación de Alfredo Guevara, director del I.C.A.I.C., quien se 
situaría entre los principales animadores de los festivales cinematográficos de Viña del Mar. Después del golpe militar en Chile, Guevara reiniciaría los festivales latinoamericanos en La Habana. «Esa es la importancia clave de Alfredo Guevara, forjador del Nuevo Cine. Mantener los contactos, realizar los festivales-encuentros, crear una Escuela de Cine modelo en América Latina, con una temática tercermundista. No crear estetas sino que revolucionarios del celuloide. Gente que luche por los cambios. Gente que no se rinda ante la presión del sistema» (Francia, 176).

\section{CINEMATOGRAFÍAS EMERGENTES}

Un importante descubrimiento del Primer Festival fue la del cineasta boliviano Jorge Sanjinés, quien ya iniciaba su exploración en un cine indigenista, volcado a representar la situación de la cultura aymara y su confrontación con el poder hegemónico de su país. Su filme Revolución, reconstituía documentalmente un momento insurreccional de los mineros del estaño. Mediante un montaje expresivo, que prescindía de textos explicativos, describía las condiciones de miseria de sus protagonistas y exaltaba la lucha política con un discurso visual que anunciaba la evolución que experimentaría el nuevo cine.

Por otra parte, el entonces esporádico cine uruguayo se hizo presente con Carlos, cine-retrato de un caminante, de Mario Handler, que sigue el trayecto de un vagabundo, excluido de una sociedad aparentemente próspera. El comienzo de este vagabundaje, según los datos biográficos que el personaje va aportando, coincide con el comienzo también del declive de la antaño próspera economía agraria uruguaya. «Deseaba presentar el retrato de una sociedad a través del estudio de un simple individuo, para llegar a lo social a través de lo personal. Puse a un lado todo mi entrenamiento científico y trabajé intuitivamente. En este caso, la investigación y el proceso creativo eran uno y lo mismo» (Handler cit. en Burton, 19).

La evolución del contexto socio-político en que se desenvuelve el cine del continente, va a traducirse en una mayor radicalización de las propuestas ideológicas del nuevo cine y ello marcará la tónica del siguiente festival, efectuado dos años después.

\section{SEGUNDO TIEMPO}

En el año que media entre uno y otro festival, la actividad política en el continente se ha hecho más intensa y ello ha repercutido en toda la dinámica cultural, especialmente en el cine. Es por esto que el Segundo Festival latinoamericano se efectúa decididamente bajo el signo de la acción política con sus propuestas revolucionarias y de cambios profundos en la sociedad. De hecho, el público de la Sala de Cine Arte se ha constituido en un interlocutor exigente y discriminante, que hace, por ejemplo, que documentales de excepción, como Araya, de la venezolana Margot Benacerraf, no sean bien recibidos por defraudar las expectativas del discurso político movilizador que se exigía entonces al documental. «Todo cine al ser vehículo de ideas y modelos culturales, e instrumento de comunicación 
y proyección social, es en primer término un hecho ideológico y, en consecuencia también un hecho político» (Solanas y Getino, 125).

Es también un festival principalmente de largometrajes de ficción, lo que cambia algunas de las estrategias comunicacionales planteadas en los debates anteriores. Ya no se confía solo en la comunicación horizontal y la exhibición para públicos deliberantes, sino que se persigue también la masividad mediante la recuperación de las salas comerciales con el formato de $35 \mathrm{~mm}$.

\section{OTRO CINE CHILENO}

Para el cine chileno significa un cambio cualitativo importante y quienes han historiado el período no vacilan en asignarle un valor inaugural: nacimiento de un nuevo cine chileno. Era, en gran medida, resultado de la experiencia dejada por el Primer Festival: las propuestas y prioridades temáticas y formales debatidas y el ejemplo de un cine que podía realizarse al margen de la industria y con medios precarios. Tres largometrajes estrenados en el festival comparten con los nuevos cines no sólo sus condiciones de producción: filmación en blanco y negro, con equipos livianos, en escenarios naturales, con participación de algunos actores no profesionales y centrados en historias que se refieren a diversas formas de marginalidad. Se trata de una nueva mirada sobre el país y sus zonas ignoradas u ocultadas por la visión institucionalizada.

Valparaíso mi amor, de Aldo Francia, cineasta que fue, a la vez, el principal impulsor de los festivales, trata de la infancia en la pobreza, excluida y empujada hacia los márgenes sociales; El chacal de Nahueltoro, de Miguel Littin, más que una requisitoria contra la pena de muerte, es la descripción de la clausura social, psicológica y moral de un marginado en condiciones extremas; Tres tristes tigres, de Raúl Ruiz, basándose en la pieza teatral de Alejandro Sieveking, caracteriza la incoherencia e inconsistencia del tejido social urbano y sus contradicciones.

Zuzana Pick, en su libro Diez años de cine chileno, describe los rasgos dominantes de estos filmes:

Los realizadores de estas películas buscaron los puntos de contacto entre la esfera ficticia de lo imaginario y la esfera cotidiana de la realidad, rompiendo las barreras que tradicionalmente separan el cine de espectáculo del cine documental. La puesta en escena de los multifacéticos aspectos de una cultura sirve como fundamento a una reflexión crítica sobre la sociedad chilena. Así el cine de acción se convierte en una crónica creativa de un proceso social (cit. en Francia, 164).

Otro filme chileno estrenado en el Festival y frecuentemente ignorado por sus historiadores fue Caliche Sangriento de Helvio Soto, un precursor del nuevo cine con sus cortometrajes de ficción. Soto inaugura un género en Chile que podríamos denominar de «revisión histórica», al recrear un episodio de la guerra del Pacífico con una mirada crítica y desmitificadora, transformando su filme en un discurso antibélico y antimilitarista. 


\section{LA HORA DE LOS HORNOS}

En el documental argentino surge una nueva propuesta con La hora de los hornos de Fernando Solanas y Octavio Getino. Caracterizado por ellos como filme-ensayo, analiza, critica, denuncia la realidad política y social de su país, agregando a la imagen testimonial un acopio de referencias históricas, ideológicas, estadísticas, sociológicas que son sometidas al juicio del espectador. Obra de más de cuatro horas de duración, era exhibida por partes y la proyección se interrumpía cada cierto tiempo para dar lugar a la reflexión o al debate. De este modo, se aproximaba al concepto acuñado por Getino, de «comunicación horizontal». Se divide en tres partes exhibidas separadamente, con títulos bastante elocuentes: «Neocolonialismo y violencia», "Acto para la liberación» $\mathrm{y}$ «Violencia y liberación». Filmada en la clandestinidad (Argentina continuaba bajo la dictadura del general Onganía), era exhibida también en esas condiciones, con públicos vinculados a instituciones universitarias, culturales o sindicales: «La hora de los hornos está destinada a procesos que se extienden a lo largo de una variedad de registros, que su agenda política es afectada por factores sociohistóricos que, a su vez, informan de su recepción y circulación» (Pick, 57).

Su estructura se afirmaba en el montaje con uso frecuente de materiales de archivo y de acuerdo a la noción eisensteniana de «montaje ideológico».

Durante sus exhibiciones, los realizadores exponían los fundamentos teóricos de su movimiento denominado «Tercer Cine», para oponerlo al cine comercial, pero también al cine de autor, preocupado principalmente de la dimensión estética de los filmes.

Resulta difícil en nuestro tiempo distinguir dentro del cine comercial y aun en gran parte del llamado "cine de autor», una obra que escape a los modelos del cine norteamericano. El dominio de éste es tal que incluso los filmes «monumentales» de la cinematografía reciente de muchos países socialistas, son a su vez monumentales ejemplos de la sumisión a todas las proposiciones impuestas por los modelos hollywoodenses que, como bien diría Glauber Rocha, dieron lugar a un cine de imitación. La inserción del cine en los modelos norteamericanos, aunque solo sea en el lenguaje, conduce a una adopción de ciertas formas de aquella ideología que dio como resultado ese lenguaje y no otro, esa concepción de la relación obra- espectador, y no otra (Solanas y Getino, 65).

Propician, en cambio, la creación colectiva, en la que intervienen los propios actores de la situación expuesta. Para caracterizar las relaciones de Latinoamérica con el mundo desarrollado, especialmente EE.UU., utilizan el término «neocolonialismo» y a partir de él realizan un diagnóstico que configura su propuesta ideológica y estética. Sus objetivos y métodos son expuestos en manifiestos y ponencias que apoyan la función didáctica de sus películas. La creación cinematográfica se hace parecida a la guerra de guerrillas, con sus ofensivas, retiradas y ocasionales derrotas, porque el cineasta es un combatiente más junto a ese pueblo que aspira a liberar:

El cine de guerrillas proletariza al cineasta, quiebra la aristocracia intelectual que la burguesía otorga a sus seguidores, democratiza. La vinculación del cineasta con la realidad lo integra más a su pueblo. Capas de vanguardia y hasta las masas, intervienen colectivamente en la obra cuando entienden que ésta es la continuidad de su lucha cotidiana. La hora de los hornos ilustra cómo un filme puede llevarse a cabo aun en circunstancias hostiles cuando cuenta con la complicidad y la colaboración de militantes y cuadros del pueblo [...] 
Nuestra época es época de hipótesis más que de tesis, época de obras en proceso, violentas, hechas con la cámara en mano y una piedra en la otra, imposibles de ser medidas con los cánones de la teoría y la crítica tradicionales (Solanas y Getino, 78).

\section{LA ESTÉTICA DE LA VIOLENCIA}

El largometraje brasilero tuvo nuevamente como su representante principal a Glauber Rocha, no solo con sus películas, sino también con la resonancia de sus planteamientos teóricos. Antonio das Mortes es la secuela de un relato iniciado con Dios y el diablo en la tierra del sol. En ella, el mercenario que ha asesinado al beato Sebastiao y al cangaceiro Corisco en aquel filme, sigue un sinuoso itinerario hasta enfrentar a sus antiguos mandantes, representantes del poder eclesial, político y económico. Compleja parábola que aventura una interpretación histórica pero que también alude a la realidad del presente brasilero. Por otra parte, el tema de Tierra en trance, situada en el presente, es directamente político. Sin embargo, la situación del Brasil obliga al realizador a encubrir lugares y personajes en la indeterminación y la alegoría:

es un trabajo que resulta de una meditación sobre el movimiento socio-político desbaratado en abril de 1964, ampliada, por lo que parece, para una visión general de la política del mundo subdesarrollado latinoamericano. En un país imaginario se confrontan un demagogo fascista y un político reformista que pretende una renovación social sin revolución, sin romper con el statu quo, por vías legales y acuerdos. Entre ellos circula un joven político [...] que quiere llevar al reformista a asumir actitudes firmes, pero es vencido por la politiquería, entendimientos, conciliaciones y capitales extranjeros... (Bernardet, 121).

Las bases teóricas en que fundamentaban estas recientes manifestaciones del cinema novo, esta vez, destinadas a conquistar las pantallas de las salas de cine, se expresaban en diagnósticos y propuestas de gran vigor retórico, como la «estética de la violencia» surgida en un texto de Glauber Rocha, donde coincide con Solanas y Getino en describir Latinoamérica como un territorio colonizado que requiere un movimiento liberador e identifica el hambre endémica de los países latinoamericanos como el factor diferenciador con el cine del primer mundo:

Por eso el hambre del latinoamericano no es solamente el síntoma alarmante de su pobreza social; es la ausencia de su sociedad. De ese modo podemos definir nuestra cultura del hambre. Ahí reside la práctica originalidad del nuevo cine con relación al cine mundial: nuestra originalidad es nuestra hambre [...] Y la más auténtica manifestación cultural del hambre es la violencia [...] pero la violencia de un hambriento no es por primitivismo; la estética de la violencia antes de ser primitiva, es revolucionaria, es el momento en que el colonizador se da cuenta de la existencia del colonizado (Cit. en Orell, 76). 


\section{CINE INDIGENISTA}

Como adelantáramos más arriba, el máximo representante del cine boliviano, Jorge Sanjinés, abordaría el tema étnico, pero enfatizando la perspectiva política y recurriendo a la ficción. En la película Ukamau (Así es) narra la historia de la violación y homicidio de una mujer aymara por parte de un mestizo. El viudo prepara pacientemente el momento en que enfrentará al asesino para cobrar venganza. Hablada en gran parte en lengua aymara, el filme resalta las profundas diferencias culturales, la indiferencia de la autoridad frente a la victimización del indígena, la desconfianza de éste y su adhesión a ritos ancestrales, como actitud reivindicativa. Según su autor, el filme «ayudó al pueblo a darse cuenta de que la lucha contra sus explotadores tendría que llegar a ser deliberadamente violenta» (Cit. en Burton 39).

Su siguiente filme, Yawar Mallku («Sangre de Cóndor») se inscribe más directamente en la reciente contingencia política. Una comunidad aymara es víctima de un experimento de esterilización forzada, en un programa llevado a cabo por el denominado «Cuerpo de Paz» del gobierno norteamericano. Alertados los indígenas, proceden a castigar a sus opresores mediante una mutilación brutal, pero equivalente en sus resultados: «El tema también proporcionó una oportunidad para dar sustancia a la noción de imperialismo, la que nuestro pueblo veía solo como una incomprensible abstracción» (cit. en Burton 40). La movilización política originada por el filme tanto en las comunidades indígenas como en las instancias gubernamentales condujo a la expulsión del país de los Cuerpos de Paz: Sangre de cóndor probó que el filme revolucionario puede ser una efectiva arma política» (cit. en Burton, 40).

De estas experiencias de Sanjinés surgirá el Grupo Ukamau, integrado, entre otros, por sus colaboradores Oscar Soria y Antonio Eguino, dedicados a la producción de filmes sobre el tema indigenista.

\section{MEMORIAS DEL SUBDESARROLLO}

La numerosa muestra de largometrajes cubanos destacó por la variedad de opciones estéticas y culturales. Memorias del subdesarrollo de Tomás Gutiérrez Alea, basada en un relato de Edmundo Desnoes, describe las vacilaciones de un intelectual de clase media cuya familia ha emigrado a Miami tras el triunfo de la revolución. Es un retrato intimista que alterna las reflexiones de su protagonista con imágenes documentales de los acontecimientos políticos que vive el país. La mirada distanciada, la reflexión autocrítica, la observación de una cotidianidad casi banal, en un lenguaje moderno constituían una verdadera nueva propuesta estética para enfrentar las relaciones entre cine y política.

La revisión crítica de su historia caracterizará varios de los filmes cubanos exhibidos. La primera carga al machete de Manuel Octavio Gómez, es una reconstrucción histórica de una acción de la guerra de 1868 revivida con las técnicas del reportaje filmado como si se tratara de un hecho actual. Lucía de Humberto Solás se organiza como un filme episódico que representa tres retratos de mujeres en distintas épocas convulsionadas por 
los acontecimientos políticos. La odisea del general José, de Jorge Fraga, «conjuga lo épico con la descripción de la naturaleza tropical, para construir un cuadro heroico» (Francia, 159).

Los nuevos documentales de Santiago Álvarez confirmaban su dominio en el filme de montaje y su capacidad de organizar imágenes heterogéneas para construir un discurso político. Desde L.B.J., una sátira del presidente de EE. UU. realizada con materiales de archivo, hasta Hanoi martes 13 sobre el bombardeo de la capital vietnamita por los aviones norteamericanos y 79 primaveras, acerca de la muerte del líder Ho Chi Minh, ambas en un registro de elaborada emocionalidad, Álvarez se mantenía fiel a una estética y a un discurso político coherentes: «son aún obras impresionantes porque en ellas uno advierte que vibra el compromiso de un hombre (no de un frío relator de supuestas verdades) empeñado en hacer valer su punto de vista, de allí que sea posible detectar ironías, deslumbramientos, dolores, alegrías, resentimientos, esperanzas, amores y todo ese largo cúmulo de pasiones que nos va conformando como seres humanos, en la vida...» (Paranaguá, 161).

El realizador Julio García Espinosa, que había incursionado en géneros como el humor cercano a la picaresca y la sátira con Aventuras de Juan Quinquin y el documental político en Tercer mundo, tercera guerra mundial, publica su polémica teoría del cine imperfecto cuyas ideas habían sido esbozadas ya en los escritos de Fernando Birri:

Hoy en día un cine perfecto — técnica y artísticamente logrado- es casi siempre un cine reaccionario $[\ldots]$

La mayor tentación que se le ofrece al cine cubano en estos momentos - cuando logra su objetivo de un cine de calidad, de un cine con significación cultural dentro del proceso revolucionario- es precisamente la de convertirse en un cine perfecto [...]

Nos preguntamos si es irremediable para un presente y un futuro realmente revolucionarios tener «sus» artistas, «sus» intelectuales, como la burguesía tuvo los «suyos». ¿Lo verdaderamente revolucionario no es intentar, desde ahora, contribuir a la superación de estos conceptos y prácticas minoritarias, más que perseguir in aeternum la "calidad artística» de la obra? La actual perspectiva de la cultura artística no es más la posibilidad de que todos tengan el gusto de unos cuantos, sino la de que todos puedan ser creadores de cultura artística (cit. en Orell, 77-79).

A partir de la idea de «democratizar el proceso creador» en oposición a un arte generado por elites, se entabló una extensa polémica que envolvía algunos de los temas más recurrentes abordados en los encuentros. ¿Qué tipo de cine realizar? ¿Para qué audiencias? ¿Qué grado de participación o interlocución debía tener el público destinatario? En la teoría de García Espinosa, se trata de aspirar a que el pueblo sea el realizador de su propio cine, diferente al arte de elites y que ese mismo pueblo sea su espectador. Allí estaría la verdadera definición de arte popular, diferente del arte de masas, el cual sería «el arte que hacen unos pocos para las masas» (cit. en Orell, 80). 


\section{CINE DE URGENCIA}

Otras cinematografías emergentes del continente respaldaban en la praxis la teoría del "cine imperfecto", subordinando la precariedad tecnológica a la urgencia de la instancia comunicadora que registraba el día a día de los procesos políticos que agitaban sus países. En Uruguay, Mario Handler, con su propuesta del «cine urgente», documentaba, con recursos mínimos, los temas conflictivos de la realidad de su país: Me gustan los estudiantes, sobre las manifestaciones callejeras de los jóvenes, Liber Arce, liberarse elegía a un líder estudiantil asesinado por la policía y El problema de la carne, que aborda la mayor huelga efectuada hasta entonces en Uruguay y que afectaba a la principal fuente de divisas del país, en la que «intenté aportar los antecedentes necesarios de la huelga a través de investigación en la historia de la industria y entrevistas con líderes sindicales» (cit. en Burton 23).

Con similar precariedad técnica, el colombiano Pedro León Giraldo realizó Camilo Torres, un homenaje documental al cura guerrillero. En Venezuela, otro uruguayo, Jorge Solé, dirigió TV Venezuela, "un análisis serio y al mismo tiempo cinematográficamente bien desarrollado, de la televisión como instrumento de colonización cultural» (Francia, 162).

\section{CONCLUSIÓN}

Para muchos de los realizadores que participaron en estos encuentros, la creación cinematográfica era parte de la acción política que ejercían en su cotidianidad y propiciaban a la vez en sus películas. Perseguidos, trabajando en la clandestinidad, filmando y exhibiendo sus obras en condiciones difíciles, conseguían plenamente esa identificación entre cine y vida sostenida por ciertas teorías. La propuesta moral, estética, política y epistemológica eran uno y lo mismo. Algunos de ellos fueron asesinados por las fuerzas a las que combatían (Vladimir Herzog, Raymundo Gleyzer, Jorge Cedrón, Jorge Müller), otros modificaron sus objetivos, como el cinema novo o el cine cubano que buscaron una hibridación entre la dimensión política y la fórmula ligera de atractivo popular, dirigida al gran público.

Con la aparición de nuevos formatos como la grabación digital, con sus equipamientos livianos y sus costos mínimos de producción, pareciera cumplirse el sueño de los documentalistas latinoamericanos. La cámara puede registrarlo todo, en cualquier lugar, no importa cuales sean las condiciones de luz, y exhibir de inmediato las imágenes y sonidos grabados. Hoy es posible el cine de la inmediatez y de la urgencia que ellos buscaban. Sin embargo el impacto cultural que suscitaron aquellos primeros festivales de cine del continente no se ha vuelto a repetir. 


\section{REFERENCIAS}

Bernardet, Jean-Claude. Brasil em tempo de cinema. Río de Janeiro: Ed. Civilizaçao Brasileira, 1967. Medio impreso.

Birri, Fernando. La Escuela Documental de Santa Fe. Santa Fe: Editorial Documento del Instituto de Cinematografía, 1964. Medio impreso.

Burton, Julianne. Cinema and social change in Latin America. Austin: University of Texas Press, 1986. Medio impreso.

Francia, Aldo. Nuevo cine latinoamericano en Viña del Mar. Santiago: CESOC, 1990. Medio impreso.

Orell, Marcia. Las fuentes del nuevo cine latinoamericano. Valparaíso: Ediciones Universitarias de Valparaíso, 2006. Medio impreso.

Paranaguá, Paulo Antonio. Cine Documental en América Latina. Madrid: Cátedra, 2003. Medio impreso.

Pick, Zuzana M. The new latin american cinema. A continental proyect. Austin: University of Texas Press, 1993. Medio impreso.

Rocha, Glauber. Revisión crítica del cine brasilero. La Habana: Ediciones ICAIC, 1965. Medio impreso.

Salem, Helena. Nelson Pereira dos Santos. Madrid: Cátedra, 1997. Medio impreso.

Solanas, Fernando y Octavio Getino. Cine, cultura y descolonización. Buenos Aires: Siglo Veintiuno, 1973. Medio impreso.

Vallejo, Gerardo. Un camino hacia el cine. Córdoba: El Cid Editor, 1984. Medio impreso.

Recepción: 29 de marzo de 2010

Aceptación: 3 de mayo de 2010 